\title{
VERBENONE PROTECTS CHINESE WHITE PINE (PINUS ARMANDII) (PINALES: PINACEAE: PINOIDEAE) AGAINST CHINESE WHITE PINE BEETLE (DENDROCTONUS ARMANDII) (COLEOPTERA: CURCULIONIDAE: SCOLYTINAE) ATTACKS
}

\author{
ZHAO, M. ${ }^{1}-$ LIU, B. ${ }^{2}-$ ZHENG, J. ${ }^{2}-$ KANG, X. ${ }^{2}-$ CHEN, H. ${ }^{1 *}$

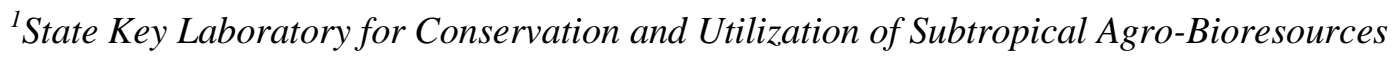 \\ (South China Agricultural University), Guangdong Key Laboratory for Innovative Development \\ and Utilization of Forest Plant Germplasm, College of Forestry and Landscape Architecture, \\ South China Agricultural University, Guangzhou 510642, China \\ ${ }^{2}$ College of Forestry, Northwest A \& F University, Yangling, Shaanxi 712100, China \\ *Corresponding author \\ e-mail: chenhuiyl@163.com; phone/fax:+86-020-8528-0256 \\ (Received 29 $9^{\text {th }}$ Aug 2020; accepted $19^{\text {th }}$ Nov 2020)
}

\begin{abstract}
Bark beetle anti-aggregation is important for tree protection due to its high efficiency and fewer potential negative environmental impacts. Densitometric variables of Pinus armandii were investigated in the case of healthy and attacked trees. The range of the ecological niche and attack density of Dendroctonus armandii in infested $P$. armandii trunk section were surveyed to provide a reference for positioning the anti-aggregation pheromone verbenone on healthy $P$. armandii trees. 2, 4, 6, and 8 weeks after the application of verbenone, the mean attack density was significantly lower in the treatment group than in the control group $(\mathrm{P}<0.01)$. At twelve months after anti-aggregation pheromone application, the mortality rate was evaluated. There was a significant difference between the control and treatment groups (chi-square test, $\mathrm{P}<0.05$ ). These results provide insight into the characteristics of infected $P$. armandii and demonstrate that anti-aggregation treatment of $D$. armandii can improve the protection of healthy $P$. armandii.
\end{abstract}

Keywords: Dendroctonus armandii, Pinus armandii, anti-aggregation, ecological niche, tree protection

\section{Introduction}

The Chinese white pine beetle (Dendroctonus armandii Tsai and Li) is a primary native pest of Chinese white pines (Pinus armandii Franch) in the Qinling Mountains of China and can be fatal to $P$. armandii individuals that are more than 30 years of age (Chen et al., 2010; Hu et al., 2016). Attack by D. armandii can result in the gradual weakening of $P$. armandii resistance, allowing the infestation of many species of bark beetles, such as Ips acuminatus, Ips sexdentatus, Hylurgops longipilis, Tomicus piniperda, and Trypodendron lineatum (Chen and Tang, 2007). Since 1970, more than $3 \times 10^{8} \mathrm{~m}^{3}$ of $P$. armandii trees (more than 30 years of age) have been harmed by $D$. armandii (Xie and Lv, 2012), and younger $P$. armandii individuals were also found to have been attacked by $D$. armandii in a recent study (Chen et al., 2015). In a time series, D. armandii, as a dominant species infecting Chinese white pines in the Qinling forest ecosystem, which attacked healthy trees and then cooperated with blue stain fungus, which resulted in an abrupt decline in resistance and triggered additional bark beetle species to secondarily attack the infected or withered host trees (Hu et al., 2016; Chen and Tang, 2007). There are significant differences between $D$. armandii and other Dendroctonus spp. in terms of their attack, similar to those between 
Dendroctonus valens and Dendroctonus ponderosae. D. valens is a secondary bark beetle and mainly invades weak, dying trees and stumps. D. ponderosae is a primary pest and mainly invades weak pines, but it has been found to invade pines during every state of an outbreak. D. armandii is not only a primary bark beetle but also affects the health of $P$. armandii. The infestation dynamics of $D$. armandii define it as a primary damaging bark beetle (Sun et al., 2013; Krause et al., 2018). Overall, D. armandii attack has caused great harm to the sustainable development of the Qinling ecosystem and has resulted in extensive economic losses (Hu et al., 2013; Pham et al., 2014).

Management measures for bark beetles in recent years have included forest management practices, chemical control and semiochemical-based trapping (Pureswaran et al., 2008; Perkins et al., 2015; Gillette et al., 2009). When D. armandii leaves its host, females first invade new individuals based on their volatiles and then release pheromones to attract more females and males (Zhao et al., 2017a), which is similar to what occurs in D. valens. Semiochemical communication among bark beetles "enables host and mate location, aggregation and resource partitioning" (Liu et al., 2013). Aggregation pheromones are considered key factors in the success of insect invasion and colonization (Faccoli and Stergulc, 2008; Blazenec and Jakus, 2009). Frontalin $+\alpha$-pinene is an aggregation pheromone released by virgin female and mated male D. armandii (Zhao et al., 2017a), and myrtenal might represent an aggregation pheromone produced by female $D$. armandii that induces aggregation effects in other females (Zhao et al., 2019). The addition of aggregation pheromones in field trapping can increase the number of trapped individuals and reduce the population density of beetles (Stephen et al., 2001; Cale et al., 2015; Shepherd and Sullivan, 2019). The anti-aggregation pheromones of bark beetles, such as verbenone in D. ponderosae and D. valens, and repellent terpene components from their hosts have been used to protect pine species from bark beetles (Gillette et al., 2006). Verbenone [(1S,5S)-4,6,6-trimethylbiclo[3.1.1]hept-3-en-2-one], a beetle-produced anti-aggregation pheromone also found in pines (Kainulainen and Holopainen, 2002) and a wide variety of angiosperms (Molyneux et al., 1980; Buttery et al., 2000; Robles et al., 2003), can be effective in limiting damage to pines by Dendroctonus spp. bark beetles (Payne and Billings, 1989; Cale et al., 2019). Verbenone has been detected using gas chromatographic and mass spectral (GC-MS) analyses of the hindguts of female beetles and the fumes emanating from $P$. armandii logs naturally attacked by D. armandii (Xie and Lv, 2012; Chen et al., 2015). In our previous study, verbenone was verified as an anti-aggregation pheromone based on electrophysiological (EAG) and Y-tube laboratory assays. In addition, field trials indicated that the addition of verbenone to the bait used to trap $D$. armandii markedly decreased the efficiency of field trapping (Zhao et al., 2017b). However, the anti-aggregation release dose, release device, release position and effect for $P$. armandii tree protection still need to be considered.

To date, comprehensive management research on $D$. armandii has focused on the identification of volatiles associated with $P$. armandii and $D$. armandii during different periods and at different locations, and field trapping of volatiles and pheromones has been carried out (Xie and Lv, 2012; Chen et al., 2015; Zhao et al., $2017 \mathrm{a}, \mathrm{b})$. On the one hand, studies on how to protect $P$. armandii by allowing it to resist attack by $D$. armandii are still lacking, and further research is needed to determine whether verbenone is responsible for the improved efficacy observed in tree 
protection studies. On the other hand, verbenone was identified as pheromone in a part of Dendroctonus spp. Even verbenone was as anti-aggregation pheromone in $D$. valens, verbenone functions as a multipurpose pheromone, attractive at very low concentrations but repellent at high concentrations (Sun et al., 2013). Thus, research on verbenone in $D$. armandii is necessary. The purpose of the study was to identify the characteristics of infested $P$. armandii and the regularities of the distribution of $D$. armandii infecting $P$. armandii. This information can provide a standard and requirements for selecting healthy experimental trees and determining the best position at which to hang anti-aggregation devices. Verbenone was further studied as an anti-aggregate in a field trial of its ability to protect trees. The results of this study could provide a basis for future studies and could be used in the biocontrol of these beetles and tree protection.

\section{Materials and methods}

\section{Study location}

The study sites were located on the southern slope of the middle Qinling Mountains, Ningshan County, Shaanxi, China, mainly in Huangguan Forest Farm (33 $42^{\prime} 23^{\prime \prime}$ $33^{\circ} 43^{\prime} 25^{\prime \prime} \mathrm{N}, 108^{\circ} 25^{\prime} 18^{\prime \prime}-108^{\circ} 25^{\prime} 46^{\prime \prime} \mathrm{E}$; the experimental area was approximately $133 \mathrm{ha})$ and Pingheliang Forest Farm $\left(33^{\circ} 22^{\prime} 00^{\prime \prime}-33^{\circ} 34^{\prime} 00^{\prime \prime} \mathrm{N}, 108^{\circ} 24^{\prime} 00^{\prime \prime}-108^{\circ} 36^{\prime} 10^{\prime \prime} \mathrm{E}\right.$; the experimental area was approximately 159 ha) (Figs. 1, 2). The survey of infected $P$. armandii and the application of the anti-aggregation pheromone were conducted in the two forest farms. The $P$. armandii trees under investigation were located from 1500 to $1800 \mathrm{~m}$ above sea level. The two forest farms were chosen because they were severely affected by $D$. armandii. The investigated $P$. armandii trees were distributed widely within the two areas.

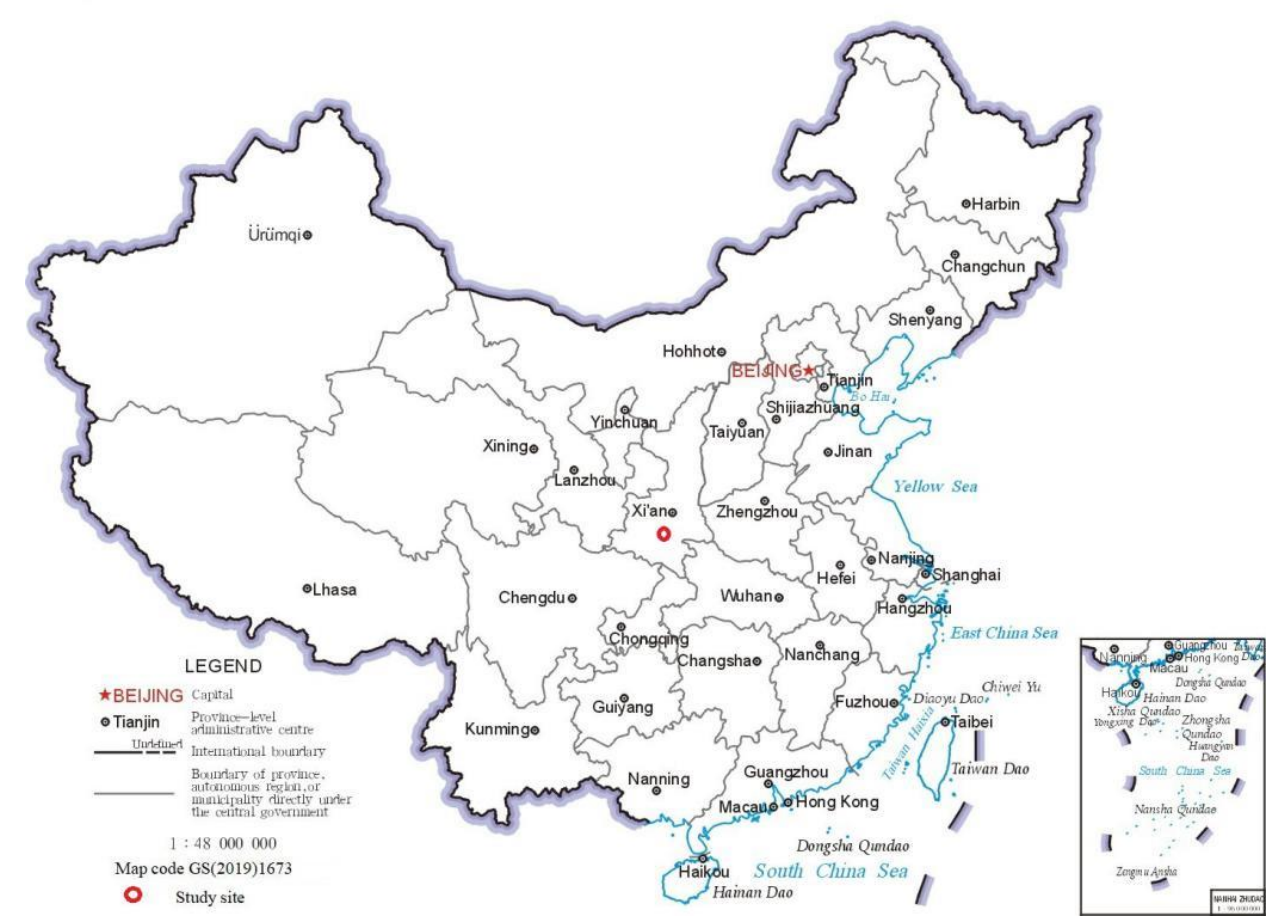

Figure 1. Study site (red circle) on a map of China. The map was downloaded from National Geomatics Center of China 


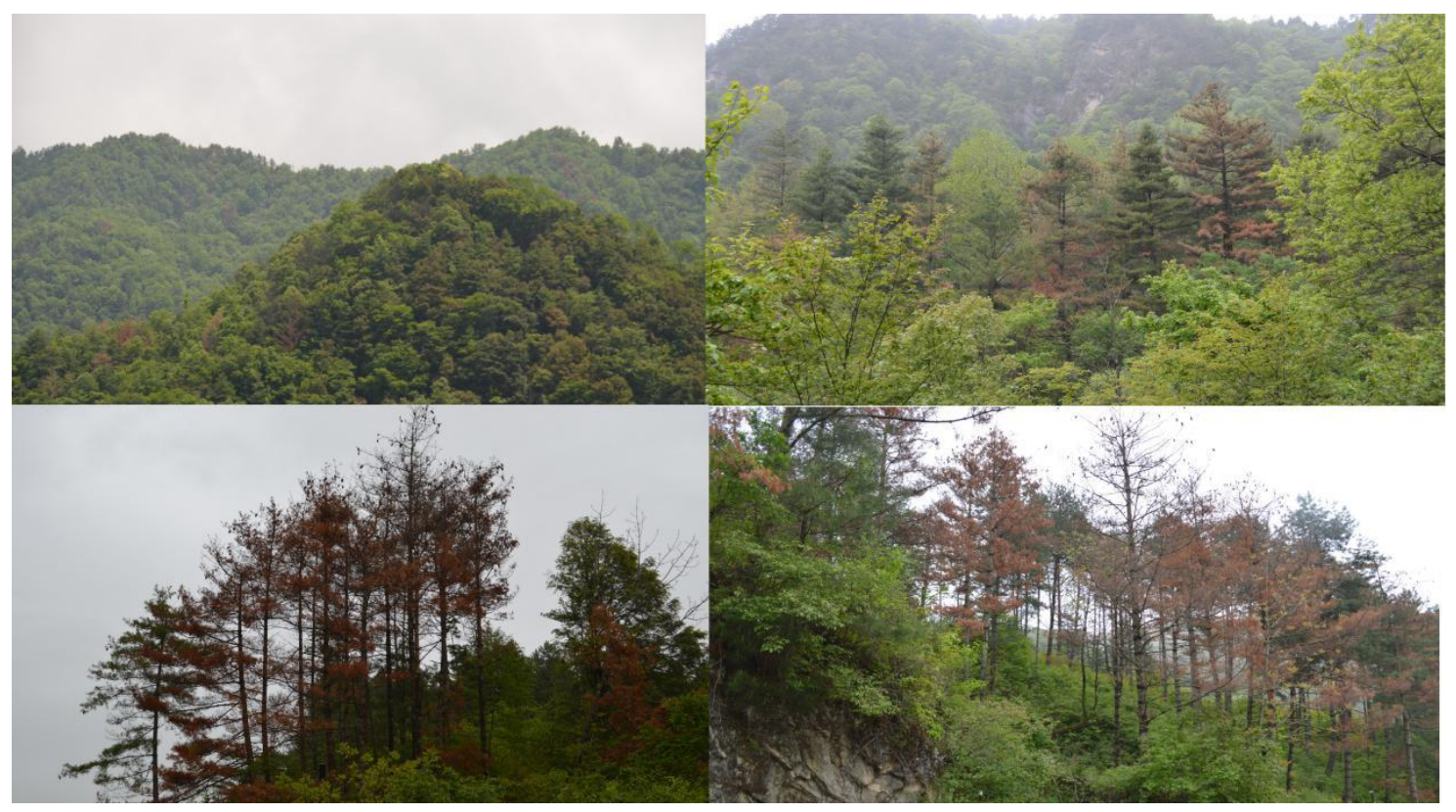

Figure 2. Some affected areas of the study sites

\section{Survey of infested Pinus armandii}

Data regarding infested $P$. armandii were collected in May 2018. At this time, the $D$. armandii individuals present were in the larval stage and constituted the offspring of $D$. armandii invading from September to October of the previous year. During the almost eight months from September 2017 to May 2018, some resinous pitch tubes fell off, and the entry holes were difficult to distinguish accurately. Therefore, second-generation larvae were used as the statistical reference for attack density. Twenty infested $P$. armandii trees were randomly selected, and the trees were separated by at least $50 \mathrm{~m}$. Diameter at breast height $(\mathrm{DBH})(\mathrm{cm})$, tree height $(\mathrm{m})$, basal area $\left(\mathrm{m}^{2} / \mathrm{ha}\right)$ and ecological niche $(\mathrm{m})$ were measured. The ecological niche in the article refer to the vertical distribution range of $D$. armandii in infested $P$. armandii trunk section. The measurement of the ecological niche and count of the attack density of $D$. armandii were performed by hewing down the infected $P$. armandii trees (adhering to the silviculture and cutting policies of the Forestry Bureau in 2018). Every infected $P$. armandii individual was equally divided into five parts in the ecological niche. For convenience, five tree sections were considered from base to crown, they were named as the bottom, lower middle, middle, upper middle and top. Each of the five parts of every tree was sampled in three locations. Ten centimeters of bark was removed by band girdling at each location, D. armandii larvae were counted, and the area of sampled bark was calculated. Samplings were done in May when beetles were in the larval stage, laying the foundation for accurate statistical analysis during the investigation period. The attack density of $D$. armandii from bottom to top was calculated based on the density of $D$. armandii larvae.

\section{Screening of vulnerable, healthy Pinus armandii}

The choice of vulnerable healthy $P$. armandii was dependent on the data for infested $P$. armandii, especially the $\mathrm{DBH}(\mathrm{cm})$, tree height $(\mathrm{m})$ and basal area $\left(\mathrm{m}^{2} / \mathrm{ha}\right)$ data. 
Vulnerable healthy $P$. armandii were defined as healthy individuals with $\mathrm{DBH}$, tree height, and basal area values that were within the ranges of values of the measured infected $P$. armandii. Forty vulnerable healthy $P$. armandii were randomly chosen for the study in June 2018. Twenty of the 40 healthy $P$. armandii were randomly allocated to the experimental group, and the others represented the control group. Additionally, the live crown ratio of the 40 trees was calculated and used to evaluate the difference between the experimental and control groups. The live crown ratio was the live crown percentage of total tree length, whereby a value near 0 indicated very little foliage and a value near 1 indicated foliage along most of the bole (Randolph, 2010; Bechtold, 2004). The distance between the vulnerable healthy $P$. armandii trees was more than $50 \mathrm{~m}$.

\section{Chemicals, pheromone formulation and attraction of Dendroctonus armandii}

The chemicals used in the field trials were $(\mathrm{R})-(+)-\alpha$-pinene $(98 \%$ chemical purity (c.p.)), (-)- $\beta$-pinene (99\% c.p.), (+)-3-carene (>98\% c.p.), myrtenal (98\% c.p.), verbenone (>93\% c.p.) and liquid paraffin (high-performance liquid chromatography (HPLC) certified) obtained from Sigma-Aldrich Co., Shanghai, China, and exobrevicomin (>95\% c.p.) and frontalin (>95\% c.p.) obtained from Contech Enterprises Inc., Delta, BC, Canada. Multiple funnel traps were used in the D. armandii attraction experiment. The traps were obtained from Sino-Czech Trading Co. Ltd., Beijing, China. $(\mathrm{R})-(+)-\alpha$-pinene, (-)- $\beta$-pinene, (+)-3-carene, frontalin, exo-brevicomin and myrtenal were chosen as the attractants at a ratio of 300:300:300:1:1:1. Frontalin, exo-brevicomin and myrtenal were authenticated as pheromones of $D$. armandii and used as the main attractant components. The host volatiles (R)-(+)- $\alpha$-pinene, $(-)-\beta$-pinene, and (+)-3carene were added as solvents. The attractant mixture was added to a $15 \mathrm{~mL}$ slowrelease plastic vial with a release speed of $200 \mathrm{mg} /$ day. The mixed reagent evaporated continuously for 8 weeks until the end of the field trial (from June 25, 2018, to August $21,2018)$. As these lures were used to aggregate but not trap $D$. armandii, the insect collection box at the base of the traps was removed. Forty lures were paired with 40 vulnerable healthy $P$. armandii and placed near the trees. The distance between each lure and the vulnerable healthy $P$. armandii individual was $10 \mathrm{~m}$. Multiple-funnel chemical attraction was applied beginning on June 25, 2018, and was used for 8 weeks.

\section{Application of the anti-aggregation pheromone verbenone}

According to the range of tree sections colonized by $D$. armandii on infested $P$. armandii trees and operational convenience, breast height was chosen as the release position for anti-aggregation pheromone. Mating disruption dispensers (tubular sustained release devices) obtained from Sino-Czech Trading Co. Ltd., Beijing, China, were used as carriers of the anti-aggregation compound and were constructed of polyvinyl chloride; the tubes were $150 \mathrm{~cm}$ long $(1.7 \mathrm{~mm}$ inner diameter, $2.5 \mathrm{~mm}$ outside diameter). Verbenone and liquid paraffin were mixed together at a ratio of 1:1. Four milliliters of the mixed reagent was injected into the mating disruption dispensers, and both ends were immediately sealed. The release speed of verbenone was approximately $100 \mathrm{mg} /$ day for the duration of the test (implantation dose divided by volatilization days). The mating disruption dispensers were refreshed every 20 days. The mating disruption dispensers with verbenone were bundled around the vulnerable healthy $P$. armandii at breast height on June 25, 2018, with verbenone released continuously for eight weeks. This release time was chosen to cover the outbreak period (July and 
August) of $D$. armandii. The number of resinous pitch tubes attacked by $D$. armandii in a band from breast height to $50 \mathrm{~cm}$ above breast height was counted every two weeks. The numerical distribution of trees in different states (alive and dead) was determined twelve months after the fourth count. Individuals of $P$. armandii with dry frass instead of resinous pitch tubes, yellowing of needle-like leaves, and hollowed-out phloem at breast height were considered dead. When there were fewer than ten resinous pitch tubes and the needle-like leaves were green, the trees were considered healthy.

\section{Experimental design, sampling and statistical analysis}

$\mathrm{DBH}$, tree height, basal area and live crown ratio were considered key factors in the process of host invasion by beetles (Gillette et al., 2006). Twenty infected $P$. armandii trees were randomly chosen as standards. The $\mathrm{DBH}$, tree height and basal area of infected $P$. armandii were assessed to identify healthy $P$. armandii similar in condition to vulnerable healthy $P$. armandii. Forty vulnerable healthy $P$. armandii trees were randomly divided into two groups to represent the experimental and control groups. Chi-square tests were performed to ensure that there were no significant differences in $\mathrm{DBH}$, tree height or basal area among the infected $P$. armandii, experimental and control groups (Fig. 3A, B, C). Considering the severe shedding of needles by infected $P$. armandii, the live crown ratio was not evaluated for these trees, but the live crown ratio of the selected vulnerable healthy $P$. armandii was calculated, and a chi-square test was performed to ensure that there was no significant difference in the live crown ratio between the experimental and control groups (Fig. 3D). All of the surveyed P. armandii in the experiment were more than $50 \mathrm{~m}$ apart. The ecological niche and change in attack density across the range of the ecological niche were also surveyed (Figs. 4, 5). This information can provide a basis for the application of and position at which to suspend verbenone on vulnerable healthy $P$. armandii.

SPSS (1999) was used for data processing, and SigmaPlot 12.0 was used to perform image processing. Mann-Whitney tests were performed to determine the significance of the differences in $\mathrm{DBH}$, tree height and basal area between the infected, control and experimental groups and to determine the significance of the differences in the live crown ratio between the control group and experimental group. The differences in attack density by $D$. armandii 2, 4, 6 and 8 weeks after treatment were tested with Mann-Whitney tests for the treatment and control groups. A chi-square test was performed to test the difference between the control and treatment groups in terms of the mortality rate.

\section{Results}

The $\mathrm{DBH}$, tree height and basal area were assessed for the infected, control and experimental groups. The live crown ratio was evaluated only for the control and experimental groups. The results of the statistical analysis showed that the mean DBH, tree height and basal area did not significantly differ between the different groups $(\mathrm{P}<0.05)$ (Fig. 3A, B, C), and the mean live crown ratio also did not significantly differ between the control and experimental groups $(\mathrm{P}<0.05)($ Fig. 3D).

The mean height (+standard error (SE)) of the infested $P$. armandii trees was $16.89+0.78 \mathrm{~m}$. The range of the ecological niche $(+\mathrm{SE})$ of $D$. armandii was $0.36+0.05$ to $12.59+0.83 \mathrm{~m}$ (Fig. 4). The attack density of $D$. armandii from bottom to top in the range of the ecological niche did not significantly differ between the groups 
( $\mathrm{P}<0.05$, least significant difference (LSD) test in SPSS), being highest in the lower middle of the tree and gradually decreasing towards the two ends (Fig. 5).
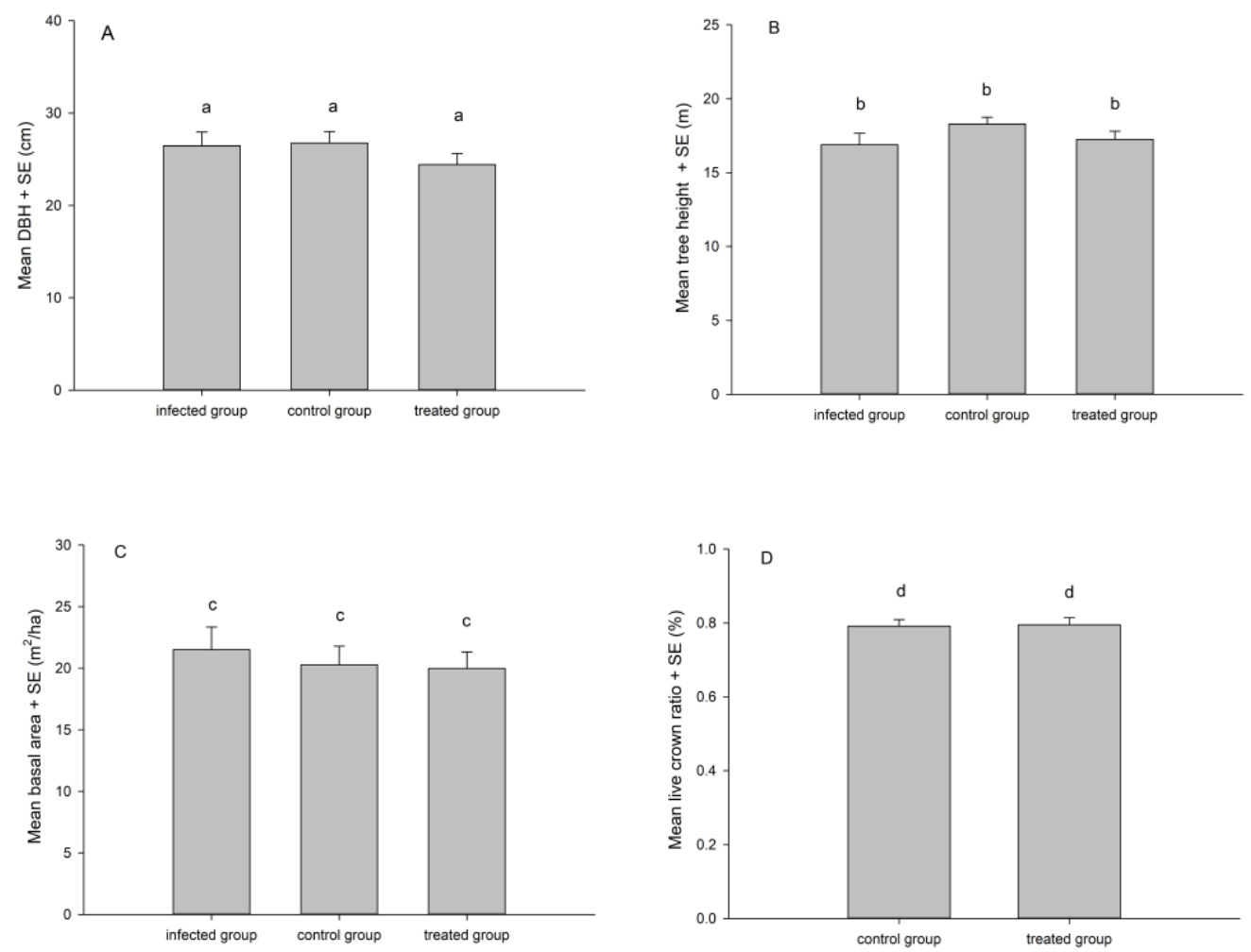

Figure 3. Mean + standard error (SE) of diameter at breast height $(D B H)(\mathrm{cm})(A)$, mean tree height $+S E(m)(B)$, and mean basal area $+S E\left(\mathrm{~m}^{2} / \mathrm{ha}\right)(C)$ of the infected, control and treated groups and mean live crown ratio $+S E(\%)(D)$ of the control and treated groups. The same letters indicate no significant difference $(P<0.05)$

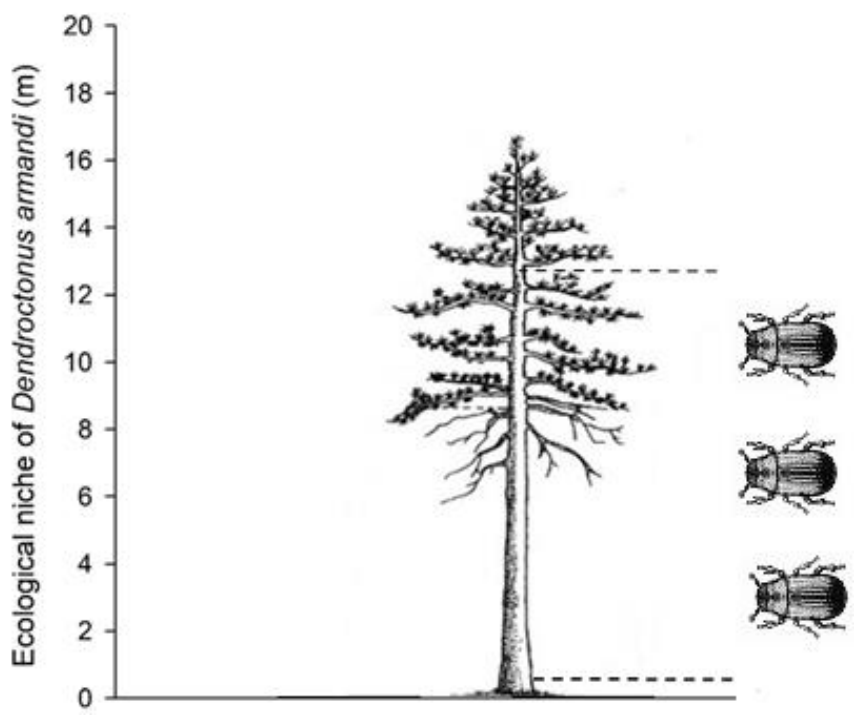

Figure 4. Ecological niche of D. armandii in an infested P. armandii trunk section (m). The three beetles indicate invading $D$. armandii, and the two dashed lines indicate the invasion scope of $D$. armandii in a $P$. armandii trunk section $(m)$ 


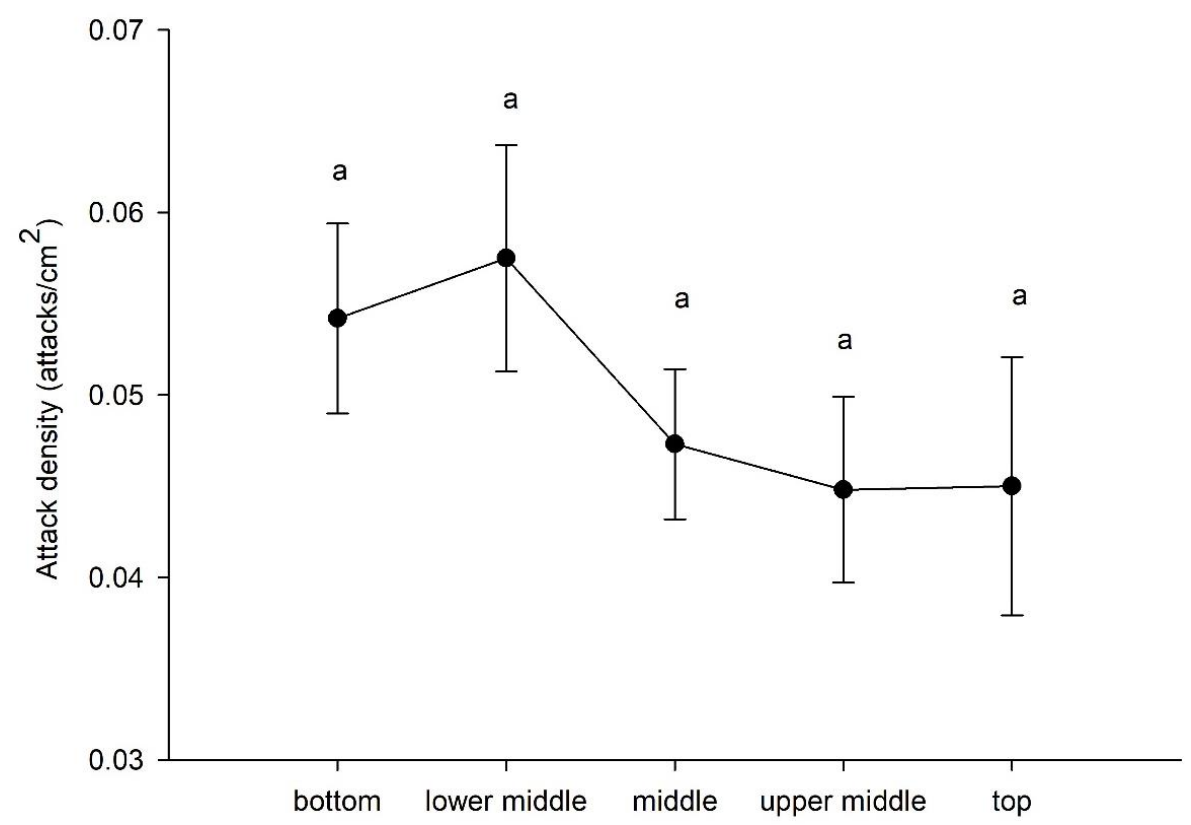

Figure 5. Attack density of D. armandii from bottom to top in infested trunk section. The same letters indicate no significant difference $(P<0.05)$

The attack density of the control group reached a high value after 2 weeks and reached saturation after 4, 6 and 8 weeks. The attack density of the treatment group gradually increased but remained consistently lower than that in the control group during the experiment (Fig. 6). The treatment group showed a significant difference from the control group in terms of the mean attack density 2, 4, 6, and 8 weeks after the application of verbenone, with the treatment group showing a significantly lower attack density (P<0.01) (Fig. 6). The experimental results regarding the mortality rate showed that $50 \%$ of the treated trees were alive, $50 \%$ of the treated trees were dead, $20 \%$ of the control trees were alive, and $80 \%$ of the control trees were dead. There was a statistically significant difference between the control and treatment groups with respect to the mortality rate (chi-square test, $\mathrm{P}<0.05$ ), with the mortality rate in the treatment group being $37.5 \%$ lower than that in the control group (Fig. 7).

\section{Discussion}

The mean $\mathrm{DBH}+\mathrm{SE}(\mathrm{cm})($ Fig. 3A), mean tree height $+\mathrm{SE}(\mathrm{m})$ (Fig. 3B), and mean basal area $+\mathrm{SE}\left(\mathrm{m}^{2} / \mathrm{ha}\right)($ Fig. $3 C)$ of the infected group reflected the common features of infected P. armandii in the Qinling Mountains. Both the DBH and live crown ratio are thought to be correlated with tree susceptibility to bark beetle attack, and the basal area of the tree surface per hectare is also thought to contribute to susceptibility to bark beetle attack (Gillette et al., 2006). The attack success rate of $D$. armandii was found to be positively correlated with stand density, tree height, tree age and DBH (Wang et al., 2010). D. armandii mainly attacks healthy $P$. armandii trees that are more than 30 years old (Chen and Tang, 2007). Although the survey of infected P. armandii (Fig. 3) and attack by $D$. armandii focused on adult trees, younger $P$. armandii, with a DBH of less than $6 \mathrm{~cm}$, were also found to be attacked by $D$. armandii in the Pingheliang Forest Farm of the Qinling Mountains in September 2018 (a personal observation). 
The attacks by $D$. armandii occur along the tree trunk from about $0.4 \mathrm{~m}$ till $14 \mathrm{~m}$. This distribution in the tree distinguishes by other bark beetles species, such as $H$. longipilis that tend to occur on the lower parts of the tree trunk, as well as Cryphalus lipingensis and Cryphalus chinlingensis which are mainly found in the upper trunk and branches. Other species, as I. acuminatus, Polygraphus sinensis, and Pityogenes japonicus are primarily distributed in the middle of the tree trunks (Chen and Tang, 2007). D. armandii is a trunk-borer bark beetle, and a certain phloem thickness is required for its overwintering and feeding (Chen and Tang, 2007). With an increase in tree height, phloem thickness gradually decreases. Therefore, the choice of the lower parts of the tree trunk is consistent with the habits of $D$. armandii. The study of the ecological niche of $D$. armandii revealed the range of activity of $D$. armandii in $P$. armandii, providing a more effective operating range for the control of $D$. armandii in infected $P$. armandii. The attack density of $D$. armandii did not differ from the bottom to the top of the tree in the range of its ecological niche; therefore, for operational convenience, the middle of the bottom of the trees (at approximately breast height) was uniformly selected for the placement of the anti-aggregation pheromone. The anti-aggregation results significantly differed between the experimental and control groups $2,4,6$, and 8 weeks after application.

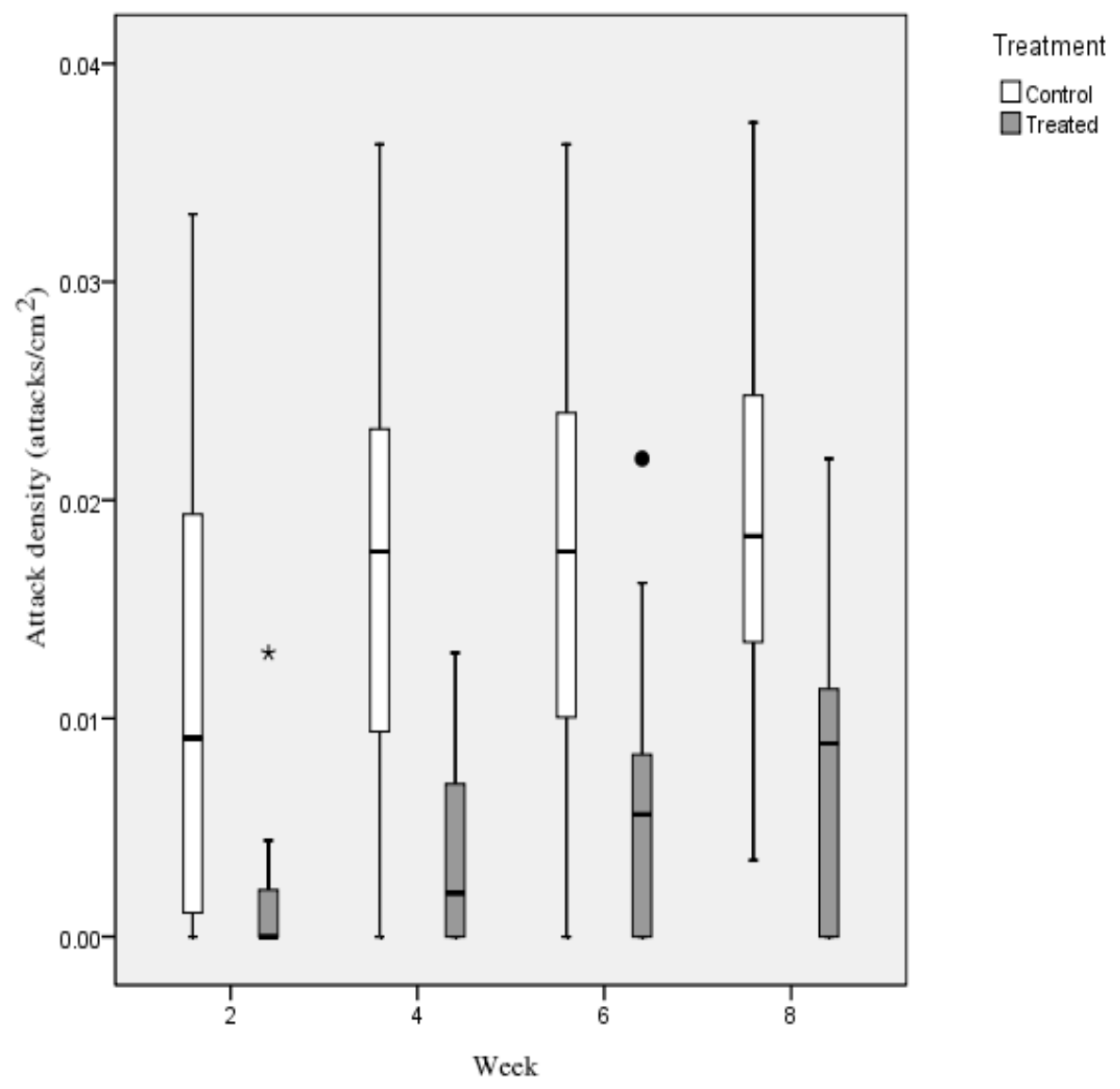

Figure 6. Mean density of attack by D. armandii 2, 4, 6 and 8 weeks after treatment. White boxes represent the interquartile range; whiskers represent the range of normal values; asterisks represent extreme values; and circles represent abnormal values. There were significant differences $(P<0.01)$ between the treatment and control groups in every case $(U$ test) 


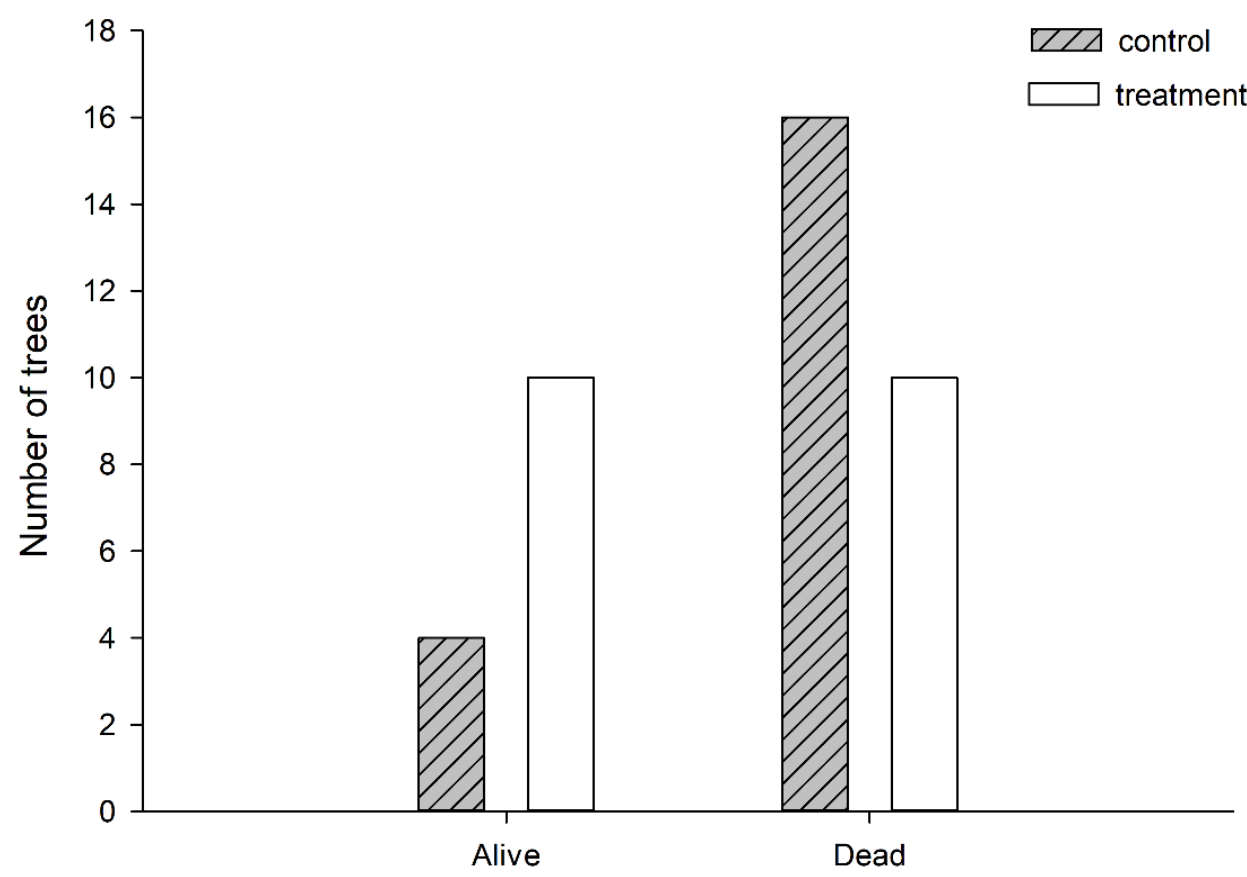

Figure 7. The numerical distribution of trees in different states (alive and dead). There was a significant difference between the control and treatment groups with regard to the mortality rate (chi-square test, $P<0.05$ )

D. armandii infestations appear to be increasing throughout the Qinling Mountains, and it is often difficult to use physicochemical methods and semiochemical traps to protect healthy Chinese white pines against attack by this beetle (Xie and Lv, 2012; Chen et al., 2015). It might be possible to use the anti-aggregation pheromone verbenone to reduce the mortality of Chinese white pines and thereby protect healthy pines. Bark beetle pheromone components can be derived from host tree precursors, often with simple hydroxylation producing the pheromone. The pheromone verbenone is produced from dietary $\alpha$-pinene in the fat bodies of some Dendroctonus spp. (Blomquist et al., 2010). Verbenone is thought to be an auto-oxidation product of verbenol and may work as an anti-aggregation signal along with frontalin (Lindgren and Miller, 2002; Cao et al., 2018). Field trapping and tree protection studies have been conducted to address the effects of verbenone on Dendroctonus brevicomis, D. ponderosae and D. valens (Gillette et al., 2006, 2012; Fettig et al., 2009b; Progar, 2003). The efficiency of verbenone pouch release devices is especially high when some Dendroctonus spp. beetles are abundant (Progar, 2005; Borden et al., 2006; Bertram and Paine, 1994). Although the production of verbenone by $D$. armandii has not been verified, verbenone was confirmed to act as an anti-aggregation pheromone in this species (Zhao et al., 2017b). In our previous study, verbenone significantly reduced the number of $D$. armandii trapped by approximately $30 \%$ in comparison to the control at two sites (Zhao et al., 2017b). Mating disruption dispensers containing insect pheromones have been produced for the management of Grapholita molesta and Cydia pomonella. In this study, mating disruption dispensers were used for the protection of $P$. armandii. Healthy $P$. armandii individuals in need of protection can be surrounded by such dispensers to allow the increased emission of antiaggregation pheromones. Of course, slow-release pouches, bottles, and tubes and Disrupt Micro-Flake can also be used for the release of anti-aggregation pheromones (Gillette et 
al., 2006). The effect of release devices on $D$. armandii still needs to be verified. Furthermore, 2, 4, 6 and 8 weeks after the aggregation of $D$. armandii and the release of verbenone, the mean attack density of the treatment group was significantly lower than that of the control group. The results of this study further show that verbenone functions as an anti-aggregation pheromone of $D$. armandii, which is consistent with the results of previous studies focusing on this species (Zhao et al., 2017b).

Verbenone was also found to exert effects on $D$. ponderosae and $D$. valens (Gillette et al., 2006, 2012). In our study, the difference in the anti-aggregation effect between the experimental and control groups was more significant in the early stage of the experiment than during the late stage of the experiment. The reason for this result may be that the attractant contained all the confirmed $D$. armandii pheromones (frontalin, exo-brevicomin and myrtenal) at the beginning of the experiment, and their attraction effects were too strong as the experiment proceeded. Nevertheless, the treatment group showed a significant difference from the control group for the data collected at the end of the experiment $(\mathrm{P}<0.01)$ (Fig. 6). Furthermore, it can be inferred that the protection effect may be stronger in the wild without artificially assisted aggregation than under experimental conditions.

In some bark beetle species, verbenone combined with multiple other components (ipsdienol and angiosperm or green-leaf volatiles) may provide enhanced efficacy over verbenone alone (Bertram and Paine, 1994; Huber and Borden, 2001; Borden et al., 2003; Pureswaran and Borden, 2004). In our previous study, myrtanol was found to be produced by infected $P$. armandii after $D$. armandii attack and had significant toxicity to $D$. armandii, especially females (Zhao et al., 2019). Thus, myrtanol has the potential to improve the anti-aggregation effect of verbenone. The mortality rate in the treatment group fell by $37.5 \%$ compared with that in the control (Figs. 7, 8). The final mortality rate revealed that the survival rate of healthy $P$. armandii could be effectively promoted by treatment with the anti-aggregation pheromone verbenone. Applied research regarding the use of verbenone to resist invasion by $D$. ponderosae and $D$. valens revealed that $70 \%$ of control trees were clearly dead, while none of the treated trees were dead (Gillette et al., 2006). The control efficiency of verbenone against $D$. armandii was inferior to that against $D$. ponderosae and $D$. valens. The reason for this result may be that the sensitivity of $D$. armandii to verbenone is inferior to that of $D$. ponderosae and $D$. valens. Of course, this speculation requires further verification. Another reason may be that the effect of the attractant was too strong. The third reason may be that the release time of verbenone was chosen to cover the outbreak period of $D$. armandii but not the whole flying period and that the mating disruption dispensers with verbenone were bundled around vulnerable healthy $P$. armandii at breast height but did not cover the entire ecological niches of $D$. armandii. This is the first tree protection study in regard to $D$. armandii, the color and shape of chosen release device and trap (Hakyemez and Cebeci, 2020; Polat, 2019), and the release speed of verbenone, and the optimal experimental conditions may not have been achieved. This study demonstrated that verbenone is effective in the protection of $P$. armandii trees, but how to enhance this effect requires further study. Further studies should explore the devices used to release verbenone, and more conservation research should be conducted to further improve the protection efficiency of $P$. armandii. 


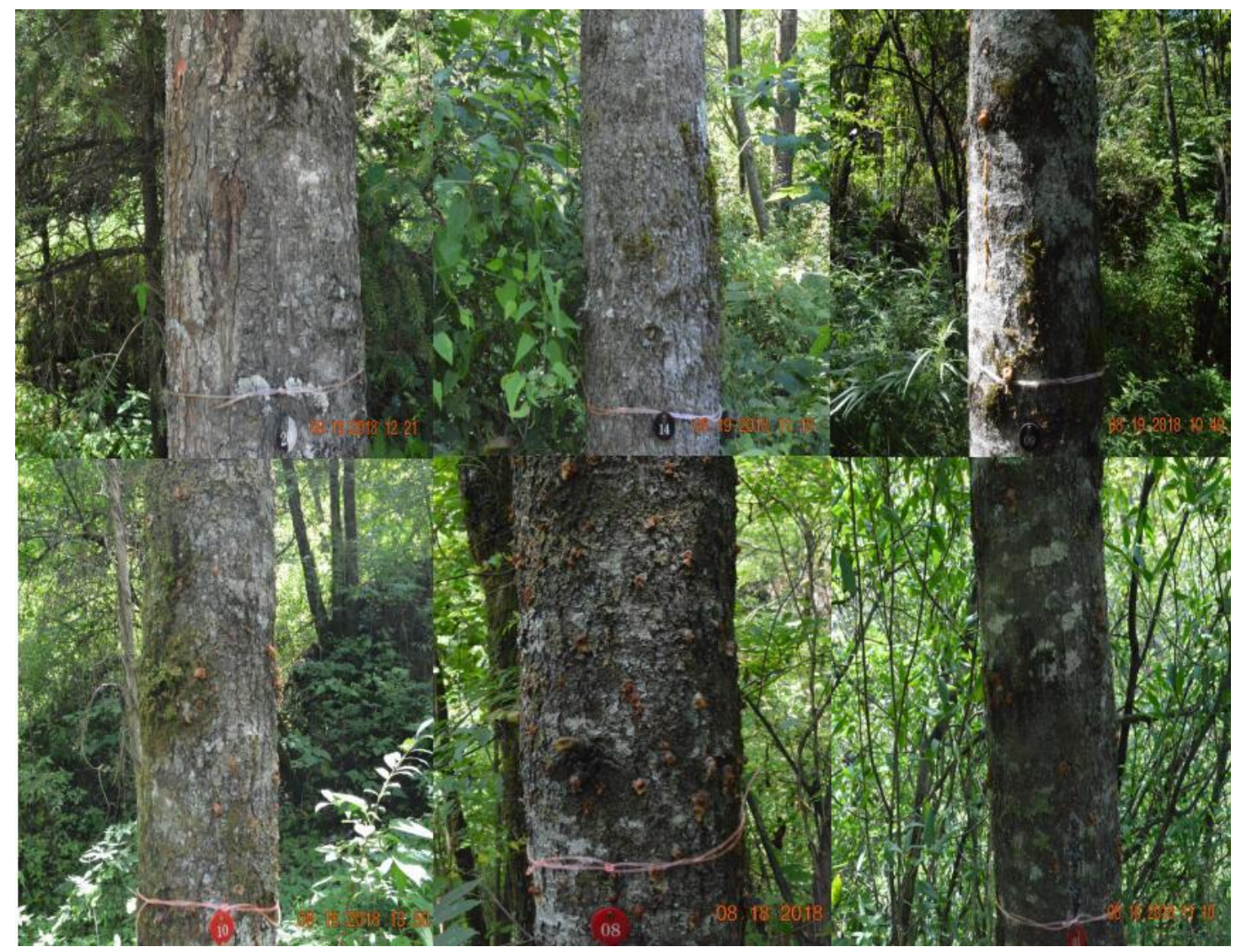

Figure 8. Experimental findings: trees with black labels were experimental trees, and trees with red label were control trees

\section{Conclusion}

Previous research confirmed verbenone as an anti-aggregation pheromone of $D$. armandii (Zhao et al., 2017b), the current study represents the first condition survey of infected $P$. armandii and the first tree protection research. The current study provides new possibilities for the protection of vulnerable healthy $P$. armandii against attack by D. armandii. We measured the $\mathrm{DBH}$, tree height and basal area of infected $P$. armandii and vulnerable healthy $P$. armandii based on these characteristics. The ecological niche range and attack density of infected $P$. armandii provide a theoretical basis for the identification of appropriate locations for the application of anti-aggregation pheromones among vulnerable healthy $P$. armandii. Dendroctonus spp. are known to use pheromones and host volatiles when attacking host trees and attracting partners (Blomquist et al., 2010). Semiochemicals might be a key factor determining successful mass colonization by Dendroctonus spp., which can overcome the defense system of host trees (Chen et al., 2015). In recent years, research has concentrated on the control and management of $D$. armandii, while the characteristics of infected $P$. armandii and the protection of healthy $P$. armandii have received less attention. Initially, it was thought that the role of verbenone was different in different Dendroctonus spp. These differences determined that research in the new species must be done step by step. The aim of this study was to determine whether verbenone has a remarkable antiaggregation effect in the complicated field environment. Our results demonstrate that the anti-aggregation pheromone verbenone can effectively lower the attack density of 
$D$. armandii and reduce the ultimate mortality of vulnerable healthy $P$. armandii. Verbenone was significantly effective in the protection of healthy P. armandii (Fig. 7). The functions of verbenone are similar among the majority of Dendroctonus spp., and the compound usually acts as an anti-aggregation pheromone (Lindgren and Miller, 2002), similar to its function in D. valens, D. ponderosae and D. brevicomis (Gillette et al., 2006; Fettig et al., 2009a). Notably, how to improve the impact (by adding other components, by changing the release rate of the lure, by changing the hanging position and so on) still needs further study.

Acknowledgements. This research was funded by the National Key Research and Development Program of China (2017YFD0600104) and the National Natural Science Foundation of China (31870636).

\section{REFERENCES}

[1] Bechtold, W. A. (2004): Largest-crown-width prediction models for 53 species in the Western United States. - Western Journal of Applied Forestry 19: 245-251.

[2] Bertram, S. L., Paine, T. D. (1994): Influence of aggregation inhibitors (verbenone and ipsdienol) on landing and attack behavior of Dendroctonus brevicomis (Coleoptera: Scolytidae). - Journal of Chemical Ecology 20: 1617-1629.

[3] Blazenec, M., Jakus, R. (2009): Effect of (+)-limonene and 1-methoxy-2-propanol on Ips typographus response to pheromone blends. - Journal of Forest Research 20: 37-44.

[4] Blomquist, G. J., Figueroa-Teran, R., Aw, M., Song, M. M., Gorzalski, A., Abbott, N. L., Chang, E., Tittiger, C. (2010): Pheromone production in bark beetles. - Insect Biochemistry and Molecular Biology 40: 699-712.

[5] Borden, J. H., Chong, L. J., Earle, T. J., Huber, D. P. W. (2003): Protection of lodgepole pine from attack by the mountain pine beetle, Dendroctonus ponderosae (Coleoptera: Scolytidae) using high doses of verbenone in combination with nonhost bark volatiles. Forestry Chronicle 79: 685-691.

[6] Borden, J. H., Birmingham, A. L., Burleigh, J. S. (2006): Evaluation of the push-pull tactic against the mountain pine beetle using verbenone and non-host volatiles in combination with pheromone baited trees. - Forestry Chronicle 82: 579-590.

[7] Buttery, R. G., Light, D. M., Nam, Y. L., Merrill, G. B., Roitman, J. N. (2000): Volatile components of green walnut husks. - Journal of Agricultural and Food Chemistry 48: 2858-2861.

[8] Cale, J. A., Taft, S., Najar, A., Klutsch, J. G., Hughes, C. C., Sweeney, J. D., Erbilgin, N. (2015): Mountain pine beetle (Dendroctonus ponderosae) can produce its aggregation pheromone and complete brood development in naïve red pine (Pinus resinosa) under laboratory conditions. - Canadian Journal of Forest Research 45: 1873-1877.

[9] Cale, J. A., Ding, R. S., Wang, F. A., Rajabzadeh, R., Erbilgin, N. (2019): Ophiostomatoid fungi can emit the bark beetle pheromone verbenone and other semiochemicals in media amended with various pine chemicals and beetle-released compounds. - Fungal Ecology 39: 285-295.

[10] Cao, Q. J., Wickham, J. D., Chen, L., Ahmad, F., Lu, M., Sun, J. H. (2018): Effect of oxygen on verbenone conversion from cis-verbenol by gut facultative anaerobes of Dendroctonus valens. - Frontiers in Microbiology 9: 464.

[11] Chen, H., Tang, M. (2007): Spatial and temporal dynamics of bark beetles in Chinese white pine in Qinling Mountains of Shaanxi Province, China. - Environmental Entomology 36: 1124-1130. 
[12] Chen, H., Li, Z., Tang, M. (2010): Laboratory evaluation of flight activity of Dendroctonus armandi (Coleoptera: Curculionidae: Scolytinae). - Canadian Entomologist 142: 378-387.

[13] Chen, G. F., Song, Y. S., Wang, P. X., Chen, J. Y., Zhang, Z., Wang, S. M., Huang, X. B., Zhang, Q. H. (2015): Semiochemistry of Dendroctonus armandi Tsai and $\mathrm{Li}$ (Coleoptera: Curculionidae: Scolytinae): both female-produced aggregation pheromone and host tree kairomone are critically important. - Chemoecology 25: 135-145.

[14] Faccoli, M., Stergulc, F. (2008): Damage reduction and performance of mass trapping devices for forest protection against the spruce bark beetle, Ips typographus (Coleoptera Curculionidae Scolytinae). - Annals of Forest Science 65: 309.

[15] Fettig, C. J., Mckelvey, S. R., Borys, R. R., Dabney, C. P., Hamud, S. M., Nelson, L. J., Seybold, S. J. (2009a): Efficacy of verbenone for protecting Ponderosa Pine stands From Western Pine Beetle (Coleoptera: Curculionidae: Scolytinae) attack in California. Journal of Economic Entomology 102: 1846-1858.

[16] Fettig, C. J., Mckelvey, S. R., Dabney, C. P., Borys, R. R., Huber, D. P. W. (2009b): Response of Dendroctonus brevicomis to different release rates of nonhost angiosperm volatiles and verbenone in trapping and tree protection studies. - Journal of Applied Entomology 133: 143-154.

[17] Gillette, N. E., Stein, J. D., Owen, D. R., Webster, J. N., Fiddler, G. O., Mori, S. R., Wood, D. L. (2006): Verbenone-releasing flakes protect individual Pinus contorta trees from attack by Dendroctonus ponderosae and Dendroctonus valens (Coleoptera: Curculionidae, Scolytinae). - Agricultural and Forest Entomology 8: 243-251.

[18] Gillette, N. E., Erbilgin, N., Webster, J. N., Pederson, L., Mori, S. R., Stein, J. D., Owen, D. R., Bischel, K. N., Wood, D. L. (2009): Aerially applied verbenone-releasing laminated flakes protect Pinus contorta stands from attack by Dendroctonus ponderosae in California and Idaho. - Forest Ecology and Management 257: 1405-1412.

[19] Gillette, N. E., Hansen, E. M., Mehmel, C. J., Mori, S. R., Webster, J. N., Erbilgin, N., Wood, D. L. (2012): Area-wide application of verbenone-releasing flakes reduces mortality of white bark pine Pinus albicaulis caused by the mountain pine beetle Dendroctonus ponderosae. - Agricultural and Forest Entomology 14: 367-375.

[20] Hakyemez, A., Cebeci, H. H. (2020): Field trial of liquid pheromone capsule (Gallopro Pinowit ${ }^{\circledR}$ ) against bark beetles in Istanbul (Turkey) forests. - Applied Ecology and Environmental Research 18: 1819-1827.

[21] Hu, X., Wang, C., Chen, H., Ma, J. (2013): Differences in the structure of the gut bacteria communities in development stages of the Chinese white pine beetle (Dendroctonus armandi). - International Journal of Molecular Sciences 14: 21006-21020.

[22] Hu, X., Li, M., Zhang, F. P., Chen, H. (2016): Influence of starvation on the structure of gut-associated bacterial communities in the Chinese White Pine Beetle (Dendroctonus armandi). - Forests 7: 126.

[23] Huber, D. P. W., Borden, J. H. (2001): Protection of lodgepole pines from mass attack by mountain pine beetle, Dendroctonus ponderosae, with nonhost angiosperm volatiles and verbenone. - Entomologia Experimentalis et Applicata 99: 131-141.

[24] Kainulainen, P., Holopainen, J. K. (2002): Concentrations of secondary compounds in Scots pine needles at different stages of decomposition. - Soil Biology \& Biochemistry 34: 37-42.

[25] Krause, A. M., Townsend, P. A., Lee, Y., Raffa, K. F. (2018): Predators and competitors of the mountain pine beetle Dendroctonus ponderosae (Coleoptera: Curculionidae) in stands of changing forest composition associated with elevation. - Agricultural and Forest Entomology 20: 402-413.

[26] Lindgren, B. S., Miller, D. R. (2002): Effect of verbenone on five species of bark beetles (Coleoptera : Scolytidae) in lodgepole pine forests. - Environmental Entomology 31: 759-765. 
[27] Liu, Z. D., Xu, B. B., Miao, Z. W., Sun, J. H. (2013): The pheromone frontalin and its dual function in the invasive bark beetle Dendroctonus valens. - Chemical Senses 38: 485-495.

[28] Molyneux, R. J., Stevens, K. L., James, L. F. (1980): Chemistry of toxic range plants: volatile constituents of broomweed (Gutierrezia sarothrae). - Journal of Agricultural and Food Chemistry 28: 1332-1333.

[29] Payne, T. L., Billings, R. F. (1989): Evaluation of (S)-verbenone applications for suppressing southern pine beetle (Coleoptera: Scolytidae) infestations. - Journal of Economic Entomology 82: 1702-1708.

[30] Perkins, D. L., Jorgensen, C. L., Rinella, M. J. (2015): Verbenone decreases Whitebark Pine mortality throughout a Mountain Pine Beetle outbreak. - Forest Science 61: 747752.

[31] Pham, T., Chen, H., Yu, J. M., Dai, L. L., Zhang, R. R., Vu, T. Q. T. (2014): The differential effects of the blue-stain fungus Leptographium qinlingensis on monoterpenes and sesquiterpenes in the stem of Chinese White Pine (Pinus armandi) saplings. - Forests 5: 2730-2749.

[32] Polat, B. (2019): Efficacy of mass trapping of tomato leafminer (Tuta absoluta) with different types and colours of traps in open- field tomato. - Applied Ecology and Environmental Research 17: 15721-15730.

[33] Progar, R. A. (2003): Verbenone reduces mountain pine beetle attack in lodgepole pine. Western Journal of Applied Forestry 18: 229-232.

[34] Progar, R. A. (2005): Five-year operational trial of verbenone to deter mountain pine beetle (Dendroctonus ponderosae; Coleoptera: Scolytidae) attack of lodgepole pine (Pinus contorta). - Environmental Entomology 34: 1402-1407.

[35] Pureswaran, D. S., Borden, J. H. (2004): New repellent semiochemicals for three species of Dendroctonus (Coleoptera: Scolytidae). - Chemoecology 14: 67-75.

[36] Pureswaran, D. S., Hofstetter, R. W., Sullivan, B. T. (2008): Attraction of the southern pine beetle, Dendroctonus frontalis, to pheromone components of the western pine beetle, Dendroctonus brevicomis (Coleoptera: Curculionidae: Scolytinae), in an allopatric zone. - Environmental Entomology 37: 70-78.

[37] Randolph, K. C. (2010): Equations relating compacted and uncompacted live crown ratio for common tree species in the south. - Southern Journal of Applied Forestry 34: 118123.

[38] Robles, C., Bousquet-Melou, A., Garzino, S., Bonin, G. (2003): Comparison of essential oil composition of two varieties of Cistus ladanifer. - Biochemical Systematics and Ecology 31: 339-343.

[39] Shepherd, W. P., Sullivan, B. T. (2019): Southern Pine Beetle (Coleoptera: Curculionidae: Scolytinae) pheromone component trans-verbenol: enantiomeric specificity and potential as a lure adjuvant. - Environmental Entomology 48: 193-201.

[40] Stephen, C. (2001): Review of the operational IPM program for the southern pine beetle. - Integrated Pest Management Reviews 6: 293-336.

[41] Sun, J. H., Lu, M., Gillette, N. E., Wingfield, M. J. (2013): Red Turpentine Beetle: innocuous native becomes invasive tree killer in China. - Annual Review of Entomology 58: 293-311.

[42] Wang, X. L., Chen, H., Ma, C., Li, Z. (2010): Chinese white pine beetle, Dendroctonus armandi (Coleoptera: Scolytinae), population density and dispersal estimated by markrelease-recapture in Qinling Mountains, Shaanxi, China. - Applied Entomology and Zoology 45: 557-567.

[43] Xie, S. A., Lv, S. J. (2012): An improved lure for trapping the bark beetle Dendroctonus armandi (Coleoptera: Scolytinae). - European Journal of Entomology 109: 569-577.

[44] Zhao, M. Z., Dai, L. L., Fu, D. Y., Gao, J., Chen, H. (2017a): Electrophysiological and behavioral responses of Dendroctonus armandi (Coleoptera: Curculionidae: Scolytinae) 
to two candidate pheromone components: frontalin and exo-brevicomin. - Chemoecology 27: 91-99.

[45] Zhao, M. Z., Dai, L. L., Sun, Y. Y., Fu, D. Y., Chen, H. (2017b): The pheromone verbenone and its function in Dendroctonus armandi (Coleoptera: Curculionidae: Scolytinae). - European Journal of Entomology 114: 53-60.

[46] Zhao, M. Z., Liu, B., Sun, Y. Y., Wang, Y. Y., Dai, L. L., Chen, H. (2019): Presence and roles of myrtenol, myrtanol and myrtenal in Dendroctonus armandi (Coleoptera: Curculionidae: Scolytinae) and Pinus armandi (Pinales: Pinaceae: Pinoideae). - Pest Management Science 76: 188-197. 